\title{
Electrolytic treatment and biosurfactants applied to the conservation of Eugenia uniflora fruit
}

\author{
Guilherme DILARRI ${ }^{1 *}$, Vinicius Luiz da SILVA ${ }^{1}$, Hengli Barbosa PECORA ${ }^{1}$, Renato Nallin MONTAGNOLLI ${ }^{1}$, \\ Carlos Renato CORSO $^{1}$, Ederio Dino BIDOIA ${ }^{1}$
}

\begin{abstract}
Microorganisms are the primary responsible for food poisoning and food spoilage. The purpose of this study was to evaluate different fruit washing methods with tap water, electrolyzed water and rhamnolipids solution produced by Pseudomonas aeruginosa LBI, in order to inhibit microbial growth. The tested organism was Eugenia uniflora. The fruits were washed and periodically inoculated into culture media to evaluate and count the colonies on the fruit surface. It was also observed the deterioration level of the fruits after each treatment. The results showed that treatment with rhamnolipids were the most efficient, inhibiting the growth of fungi and bacteria. The electrolyzed water proved to be very efficient in bacterial inhibition at the initial time, but in the final time it did not present any inhibitory effect. The electrolyzed water was also not effective in eliminating fungus. Washing with tap water was the less efficient treatment of all. The only treatment that showed an increased durability has been with rhamnolipids, increasing shelf life by up to two days. Thus rhamnolipids are the most recommended method for fruits sanitation.
\end{abstract}

Keywords: electrolyzed water; food; microorganism; Pseudomonas aeruginosa; rhamnolipid.

Pratical Application: Different washing techniques were tested, including electrolyzed water and rhamnolipids solution produced by the Pseudomonas aeruginosa. The Eugenia uniflora fruit, popularly known as pitanga, was selected as our test-organism. We evaluated which technique had a greater capacity for conservation and therefore promoted increased shelf life strategies which is a significant result for fruit marketing. The results showed that rhamnolipids treatment added extra two days of shelf life to the fruits, and also lowered the number of microbial colonies, indicating possible way to inhibit pathogens microorganisms into fresh foods.

\section{Introduction}

Food contamination is a major problem in the food industry. Microorganisms are the primary responsible for infections and food poisoning. On average, Brazil has 570.000 cases of hospitalizations due to food poisoning per year (Carmo et al., 2005). Diseases caused by contamination, mainly from fresh and uncooked products, are constant concerns from the government and industries (Huang et al., 2008).

Another microbe related problem is food waste, as quality degeneration are mostly due to microorganisms (Marriott \& Gravani, 2006). Fruits and vegetables end up losing important properties and rot before they reach consumers (Moura et al., 2007).

The food industry often uses typical techniques of sanitization to avoid these problems, e.g., the addition of chlorine compounds, organic acids, trisodium phosphate, iodine solutions and ammonia compounds (Hricova et al., 2008). However, such techniques have various side effects that cause discoloration of the food and chemical residue deposition. Therefore it becomes necessary to develop new techniques that eliminate microorganisms in food and increase its shelf life, without presenting such side effects.
The electrolyzed water is a new technique that has shown satisfactory results in the elimination of microorganisms in fruit and vegetables, without side effects (Al-Haq et al., 2005; Guentzel et al., 2008; Stopforth et al., 2008). Advantages of the electrolyzed water include its low cost and no reported impact to the environment or human health (Hricova et al., 2008).

Another product that has great potential for food sanitization are surfactants. These compounds have attracted attention due to their antimicrobial activity and low toxicity, allowing the usage against phyto-pathogenic microorganisms. According to Kim et al. (2000), rhamnolipids were used for resisting fungi and soft spots on tomatoes and apples.

Rhamnolipids, which are a type of surfactant, can further be used for the protection of vines against attack by Botrytis cinerea, because they inhibit spore germination and mycelial growth (Varnier et al., 2009). Vatsa et al. (2010) reports the antifungal rhamnolipid activity against various fungal plants pathogens such as Botrytis sp, Rhizoctonia sp, Pythium sp, Phytophtora sp. e Plasmopara sp. According to Gomes \& Nitschke (2012), the surfactin and rhamnolipid surfactants can be used not only to remove already established biofilms, but also provide a treatment 
capable of modifying surface properties. This type of treatment hinders the subsequent formation of bacterial films generated by Staphylococcus aureus, Listeria monocytogenes and Salmonella Enteritidis, pathogens that are usually associated with food.

Considering microbial activity on food and the means to mitigate its effect, this study aimed to evaluate the potential for microbial inhibition by rhamnolipids and electrolyzed water by comparing the efficiency of two techniques. We evaluated which technique also has a greater capacity for conservation of food and therefore promoted increased shelf life. Eugenia uniflora, popularly known as pitanga, was selected as our test-organism. The fruit $E$. uniflora flavor is very appreciated, but when ripe it tends to rot quickly, due to its fragile vegetable tissue structure (Fiuza et al., 2008).

\section{Materials and methods}

\subsection{Electrolysis}

The generation of electrolyzed water involved $30 \mathrm{~g} \mathrm{NaCl}$ added to $500 \mathrm{~mL}$ of distilled water in a cell enclosing titanium (Ti) electrodes covered by positively and negatively charged $\mathrm{TiO}_{2}$ and $\mathrm{RuO}_{2}$ (anode and cathode with geometric area of $40.6 \mathrm{~cm}^{2}$ ), connected to a source of direct current (Dawer, FCC-3005D). Attached to the electrolytic cell we used a magnetic stirrer to maintain the homogeneity of the resulting electrolyzed water (Figure 1). The electrolysis occurred during 5 minutes in $1 \mathrm{~A}$. Analyzes were carried to monitor $\mathrm{pH}$ and conductivity of the $\mathrm{NaCl}$ solution before and after electrolysis.

\subsection{Fruit selection}

Fruits used in this study were collected directly from the São Paulo State University (UNESP) orchard, located at Rio Claro - SP experimental garden ( $\left.22^{\circ} 23^{\prime} 47.4^{\prime \prime} \mathrm{S} 47^{\circ} 32^{\prime} 40.0^{\prime \prime} \mathrm{W}\right)$. The plants did not undergo any chemical pesticide treatment or had the addition of chemical fertilizers. Only the ripe fruit, red, without puncturing or deformation were sampled. Fruit size and shape were approximately homogeneous. The tests were carried out immediately after collection.

\subsection{Production and purification of rhamnolipids}

The microorganism used in the experiments was Pseudomonas aeruginosa LBI. These bacteria were obtained from cryogenic tubes containing glycerol $20 \% \mathrm{v} . \mathrm{v}^{-1}$, stocked at $-20^{\circ} \mathrm{C}$.

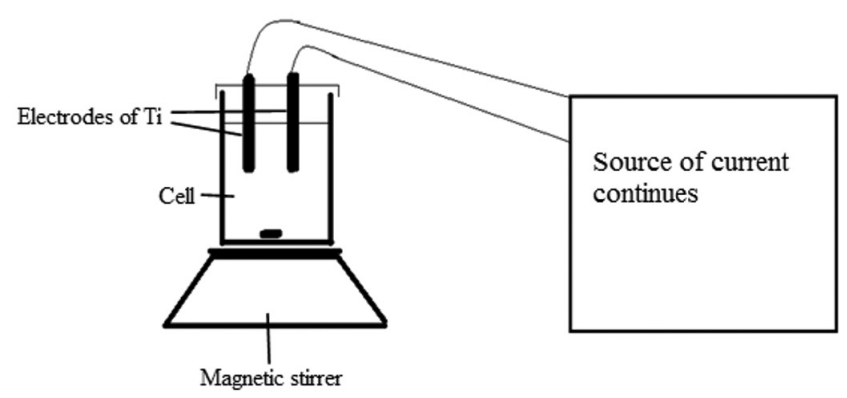

Figure 1. Electrolytic treatment setup.
The culture medium used was a calcium-free phosphate buffered mineral, containing (g. $\left.\mathrm{L}^{-1}\right): \mathrm{MgSO}_{4} 7 \mathrm{H}_{2} \mathrm{O}-0.05$, $\mathrm{KCl}-0.1, \mathrm{NaNO}_{3}-1.5$, phosphate buffered $0.1 \mathrm{M} \mathrm{pH} 6.5$ and $1 \mathrm{~mL} \mathrm{~L}^{-1}$ the solution of trace elements. This solution consists of $\left(\mathrm{g} . \mathrm{L}^{-1}\right)$ : sodium citrate dehydrate $-2.0, \mathrm{FeCl}_{3} 6 \mathrm{H}_{2} \mathrm{O}-0.28$, $\mathrm{ZnSO}_{4} 7 \mathrm{H}_{2} \mathrm{O}-1.4, \mathrm{CoCl}_{2} 6 \mathrm{H}_{2} \mathrm{O}-1.2, \mathrm{CuSO}_{4} 5 \mathrm{H}_{2} \mathrm{O}-1.2, \mathrm{MnSO}_{4}$ $\mathrm{H}_{2} \mathrm{O}-0.8$ and $125 \mathrm{~g} \mathrm{~L}^{-1}$ of soybean oil.

For purification of the rhamnolipids, we used a cell free broth which was mixed to n-hexane at a 1:1 ratio, then stirred vigorously until homogeneous. The mixture was left to equilibrate until phase separation. The organic phase containing $n$-hexane/oil was discarded. We further added $\mathrm{H}_{3} \mathrm{PO}_{4} 85 \%$ 1:100 $\left(\mathrm{v} . \mathrm{v}^{-1}\right)$ to the aqueous phase, leading to the precipitation of rhamnolipids. For the extraction of the surfactant we used ethyl acetate 1:1, $25 \%\left(\mathrm{v} \cdot \mathrm{v}^{-1}\right)$, stirred for 10 minutes. Afterwards, the mixture was kept at rest, as the upper stage for evaporation of the solvent was removed in rotary evaporator, thus yielding the rhamnolipid. The extraction procedure with ethyl acetate was repeated with the lower phase as described by Lovaglio et al. (2014).

\subsection{Fruit washing}

The fruit durability time was observed in two control groups of 30 fruit each. The fruits were placed in a Becker flask using a porous membrane on top as cover. One group was washed with tap water, whereas the other group has not undergone any washing process. The observation was carried out every 24 hours, with the final time period in which all the fruits would present the appearance of decay. For the wash test we used three groups containing a total of 30 fruits per treatment.

The first group underwent washing with $500 \mathrm{~mL}$ of tap water and then submerged in contact with the water for 5 minutes. This treatment intended to simulate the usual homemade washing procedure (Marriott \& Gravani, 2006).

The second test group was washed with $500 \mathrm{~mL}$ of electrolyzed water and then submerged for 5 minutes. In the third test group, a $1 \mathrm{~g} \mathrm{~L}^{-1}$ solution of rhamnolipid was added to the washing procedure. The fruits were submerged for 5 minutes in this solution.

After the washing process, all the beakers were determined by the end time at room temperature $\left( \pm 25^{\circ} \mathrm{C}\right)$. Every 24 hours the fruit treatments were individually analyzed, checking their state of deterioration and screening the surface coverage by fungi and bacteria. The parameters we analyzed were fractures, deterioration of internal fruit, color and consistency. Each of these parameters were ordered in a 1-5 scale. According to the scores obtained the samples were classified as bad (if the parameters reached most notes 4 and 5), medium (Notes 2 and 3 ) and good (Notes 1 and 0 ), according to the analysis period.

\subsection{Microbiological analysis}

It was used in the culture media Nutrient Agar (NA) to view the growth of bacteria, and Sabouraud agar with chloramphenicol medium $(0.15 \%)$ for growth of fungi.

After washing the fruit in the respective treatments, we used sterile swabs in the samples and inoculated them in culture 
media. Then the plates were incubated for 24 hours at $28{ }^{\circ} \mathrm{C}$. After this period, the colony forming units (CFU) of fungi and bacteria were counted. This procedure was done at the initial time and the end time of sampling to determine the difference in the number of microorganisms before and after the studied process. The experiment was conducted in four replicates each treatment and plate.

\section{Results and discussion}

The $\mathrm{pH}$, conductivity and temperature of the solutions used for each treatment are shown in Table 1.

The changes in the physical and chemical characteristics of electrolyzed water, especially in its $\mathrm{pH}$ value, indicated the occurrence of $\mathrm{NaCl}$ dissociation forming hypochlorous acid $\mathrm{HOCl}$ and sodium hydroxide $\mathrm{NaOH}$. The electrolyzed solution tends to dissociate into acid solution from the anode (at $\mathrm{pH} 2$ to 3 ) and the cathode basic solution having a $\mathrm{pH}$ ranging from 10 to 13 , thus altering initial $\mathrm{pH}$ values (Hricova et al., 2008). The values shown by rhamnolipids demonstrated a more acidic $\mathrm{pH}$ and a slightly lower conductivity of electrolyzed water.

The durability of the fruit with minimal processing, without passing by any washing process, rot in 3 days. However, when washed with tap water durability is longer, rotting only after 4 days. Due to the addition of chlorine in water treatment, tap water presents a minor microbiological inhibition (Henrique et al., 2014). Thus the end time used for the sample was 4 days.

The results of the daily analysis concerning the characteristics of the fruit after washing are shown in Figure 2.

Table 1. Physical and chemical parameters of water used in fruit washing.

\begin{tabular}{lccc}
\hline & $\begin{array}{c}\text { Conductivity } \\
\left(\mathrm{mS} \mathrm{cm}^{-1}\right)\end{array}$ & $\mathrm{pH}$ & $\begin{array}{c}\text { Temperature } \\
\left({ }^{\circ} \mathrm{C}\right)\end{array}$ \\
\hline Tap water & 0.5106 & 6.02 & 23 \\
Electrolyzed water & 78.62 & 11.02 & 36 \\
Rhamnolipid solution & 78.30 & 6.4 & 25 \\
\hline
\end{tabular}

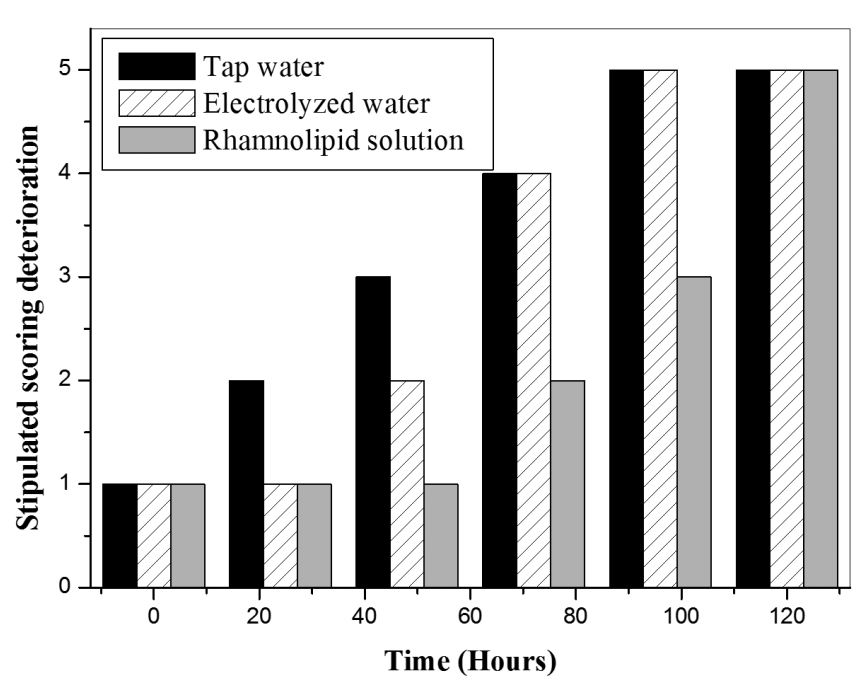

Figure 2. E. uniflora deterioration after each treatment.
After 24 hour treatments with rhamnolipids and electrolyzed water, fruits still showed good consistency, without any sign of deterioration. Simultaneously, the treatment with tap water already had decay characteristics. At 48 hours it was already observed fungal growth in the treatment rinsed with tap water, whereas treatment with electrolyzed water had small disruptions in fruits. Samples treated with rhamnolipids still had a good consistency without signs of deterioration. After 72 hours both treatments with tap water and electrolyzed water showed signs of mold growth, also presenting a slimy layer on the fruit. Bacterial growth in fruit is characterized by the slimy state of the surface of the food (Ogodo et al., 2015). At this time, the fruits treated with rhamnolipids solution began to present decay signals, such as color change and disruption of fruit probably caused by a subsequent colonization by microorganism since all the fruit submitted to treatments were not kept sterile conditions, although neither in extreme temperature, humidity and luminosity conditions.

After 96 hours all fruits treated with tap water and electrolyzed water were rotten. At that time colonies of mold and mildew started to appear at rhamnolipids treated fruits. At our final measurement, after 120 hours, every fruit treatment with rhamnolipids was rotten.

It was noted that the electrolyzed water slowed the decay of fruits, but its effect was reduced over time. The antimicrobial effect of electrolyzed water is momentary, so the application must be made immediately before consumption or packaging of food (Stopforth et al., 2008). After the formation of chemical groups $\mathrm{HOCl}$ and $\mathrm{NaOH}$, they tended to fade naturally over time, so the electrolyzed water adds a reasonable amount of shelf life due to limited antimicrobial effect (Hricova et al., 2008).

Treatment with rhamnolipids presented satisfactory results, extending the durability of fruits more than two days compared to treatment with tap water. The rhamnolipids were a powerful agent in the inhibition of bacteria and molds, as also reported by Murray et al. (2006). Another property of rhamnolipids is the formation of biofilms on materials, acting as an antioxidant and antimicrobial agent (Barros et al., 2007), thus aiding in E. uniflora conservancy data obtained in this study.

The CFU growth results of bacteria and fungi on fruit samples are shown in Table 2.

The water supply initially showed low antimicrobial effect, and the fungus growth was high from the start. And at the end of treatment the colonies numbers were too high.

Treatment with electrolyzed water showed an effective action against bacteria at initial time, almost completely inhibiting growth. However, at the end of the experiment colony numbers were as large as the treatment with tap water, showing that the inhibitory effect observed at the initial time of washing did not persist. Probably bacterial spores were not fully removed during washing, hence leading to bacterial growth after the effect of the electrolyzed water treatment ceased.

One of the disadvantages of using electrolyzed water is their lack of effectiveness in eliminating bacterial spores (Pintaric et al., 2015). We only observed in our experiment short term effects of electrolyzed water in food preservation. Furthermore, the results 
Table 2. Count of colony forming units in each treatment.

\begin{tabular}{lccccc}
\hline & \multicolumn{2}{c}{ Bacterial Count } & & \multicolumn{2}{c}{ Fungal Count } \\
\cline { 2 - 3 } \cline { 5 - 6 } & Start time & Final time & & Start time & Final time \\
\hline Tap water & 65 & Uncountable & & 299 & Uncountable \\
Electrolyzed water & 5 & Uncountable & & 83 & 476 \\
Rhamnolipid & 2 & 87 & 49 & 62 \\
\hline
\end{tabular}

showed that the electrolyzed water inhibited more than half of the fungi colonies in comparison with the treatment using tap water. Still, at the end of the experiment, large number of growth fungus colonies were observed, indicating that some colonies initially and probably some mold spores were alive in fruits after treatment. In this case we can say that electrolyzed water is not the best treatment to inhibit fungi. Eukaryotic microorganisms are much harder to remove, due to the resistance of their spores, and their cell membranes with highly heterogeneous composition (Tortora et al., 2012).

Rhamnolipids treatment proved to be highly effective in inhibiting bacterial growth, eliminating almost all bacterial colonies in initial measurements. Unlike other treatments, the number of colonies was not very high in the final time, showing that even after four days rhamnolipids kept its effect of bacterial inhibition. The rhamnolipids also proved to be the best treatment for inhibiting fungal growth, with lower growth of colonies compared to other treatments. Another major difference in fungal colonies found in rhamnolipid treated samples was that the majority of the colonies were yeasts, with very few filamentous fungi. This proves that the rhamnolipids are effective in eliminating bacteria, molds and filamentous fungi, however it presents a low efficacy in inhibiting yeast cell growth in fruits.

\section{Conclusion}

We conclude that treatment with rhamnolipids was more effective against microbial inhibition, achieving inhibits the growth of fungi and bacteria in E. uniflora fruits. The treatment with the rhamnolipids extended food durability, increasing its shelf life in two days. This occurred due to surface tension interactions caused by rhamnolipids, and was therefore a more advantageous to technique than the others. However, rhamnolipids were ineffective in inhibiting yeast growth and therefore not recommended to eliminate this microorganism.

The electrolyzed water is a powerful agent in bacterial inhibition, but its inhibitory factor is brief, leaving food vulnerable to the action of other microorganisms. Although reducing the numbers of fungal colonies, the electrolyzed water is not the best agent to eliminate such organisms. As molds and filamentous fungi are the main agents in the deterioration of fruit, electrolyzed water ends up not being the best treatment for the sanitization of these foods.

\section{Acknowledgements}

Support from the Brazilian foresting agencies: Coordenação de Aperfeiçoamento do Pessoal de Nível Superior (CAPES) - Brazil.

\section{References}

Al-Haq, M. I., Sugiyama, J., \& Isobe, S. (2005). Applications of electrolyzed water in agriculture and food industries. Food Science and Technology Research, 11, 135-150.

Barros, F. F. C., Quadros, C. P., Maróstica, M. R. M. Jr, \& Pastore, G. M. (2007). Surfactina: propriedades químicas, tecnológicas e funcionais para aplicações em alimentos. Quimica Nova, 30, 409-414. http:// dx.doi.org/10.1590/S0100-40422007000200031.

Carmo, G. M. I., Oliveira, A. A., Dimech, C. P., Santos, D. A., Almeida, M. G., Berto, L. H., Alves, R. M. S., \& Carmo, E. H. (2005). Vigilância epidemiológica das doenças transmitidas por alimentos no Brasil, 1999-2004. Boletim Eletrônico Epidemiológico, 6, 1-7.

Fiuza, T. S., Rezende, M. H., Saboia-Morais, S. M. T., Bara, M. T. F., Tresvenzol, L. M. F., \& De Paula, J. R. (2008). Caracterização farmacológica das folhas de Eugenia Uniflora L. (Myrtaceae). Revista Eletrônica de Farmácia, 2, 1-11.

Gomes, M. Z. V., \& Nitschke, M. (2012). Evaluation of rhamnolipid and surfactin to reduce the adhesion and remove biofilms of individual and mixed cultures of food pathogenic bacteria. Food Control, 25(2), 441-447. http://dx.doi.org/10.1016/j.foodcont.2011.11.025.

Guentzel, J. L., Lam, K. L., Callan, M. A., Emmons, S. A., \& Dunham, V. L. (2008). Reduction of bacteria on spinach, lettuce, and surfaces in food service areas using neutral electrolyzed water. Food Microbiology, 25, 36-41.

Henrique, I. N., Sousa, J. T., Souto, A. L. F., Leite, V. D., \& Lopes, W. S. (2014). Wastewater treatment in recycling system using anaerobic anoxic reactor followed by aerobic reactor with support. Science \& Engineering Journal, 23, 103-113.

Hricova, D., Stephan, R., \& Zweifel, C. (2008). Electrolized water and its application in the food industry. Journal of Food Protection, 71(9), 1934-1947. PMid:18810883.

Huang, Y., Hung, Y., Hsu, S., Huang, Y., \& Hwang, D. (2008). Aplication of electrolyzed water in food industry. Food Control, 19(4), 329-345. http://dx.doi.org/10.1016/j.foodcont.2007.08.012.

Kim, B. S., Lee, J. Y., \& Hwang, B. K. (2000). In vivo control and in vitro antifungal activity of rhamnolipid, a glycolipid antibiotic, against Phytophthora capsici and Colletotrichum orbiculare. Pest Management Science, 56(12), 1029-1035. http://dx.doi.org/10.1002/15264998(200012)56:12<1029::AID-PS238>3.0.CO;2-Q.

Lovaglio, R. B., Silva, V. L., Capelini, T. L., Eberlin, M. N., Hausmann, R., Henkel, M., \& Contiero, J. (2014). Rhamnolipids production by a Pseudomonas aeruginosa LBI mutant: solutions and homologs characterization. Tenside Surfactants Detergents, 51, 397-405. http:// dx.doi.org/10.3139/113.110321.

Marriott, N. G., \& Gravani, R. B. (2006). Principles of food sanitation. New York: Springer.

Moura, S. C. S. R., Berbari, S. A. G., Germer, S. P. M., Anjos, V. D., Almeida, M. E. M., \& Fefim, D. A. (2007). Determinação da vidade-prateleira de maçã-passa por testes acelerados. Food Science and Technology (Campinas.), 27(1), 141-148. http://dx.doi.org/10.1590/ S0101-20612007000100025. 
Murray, P. R., Rosenthal, K. S., \& Pfaller, M. A. (2006). Microbiologia médica. Rio de Janeiro: Elsevier.

Ogodo, A. C., Ugbogu, O. C., Ugbogu, A. E., \& Ezeonu, C. S. (2015). Production of mixed fruit (pawpaw, banana and watermelon) wine using Saccharomyces cerevisiae isolated from palm wine. SpringerPlus, 4(1), 683. http://dx.doi.org/10.1186/s40064-015-14758. PMid:26576326.

Pintaric, R., Matela, J., \& Pintaric, S. (2015). Suitability of electrolyzed oxidizing water for the disinfection of hard surfaces and equipment in radiology. Journal of Environmental Health Science \& Engineering, 13(1), 6. http://dx.doi.org/10.1186/s40201-015-0160-8. PMid:25642329.

Stopforth, J. D., Mai, T., Kottapalli, B., \& Samadpour, M. (2008). Effect of acidified sodium chlorite, chlorine, and acidic electrolyzed water on Escherichia coli O157:H7, Samonella, and Listeria monocytogenes inoculated onto leafy greens. Journal of Food Protection, 71(3), 625628. PMid:18389712.

Tortora, G. J., Funke, B. R., \& Case, C. L. (2012). Microbiologia. Porto Alegre: Artmed.

Varnier, A. L., Sanchez, L., Vatsa, P., Boudesocque, L., Garcia-Brugger, A., Rabenoelina, F., Sorokin, A., Renault, J. H., Kauffman, S., Pugin, A., Clement, C., Baillieul, F., \& Dorey, S. (2009). Bacterial rhamnolipids are novel MAMPs conferring resistance to Botrytis cinerea in grapevine. Plant, Cell \& Environment, 32(2), 178-193. http://dx.doi.org/10.1111/j.1365-3040.2008.01911.x. PMid:19021887.

Vatsa, P., Sanchez, L., Clement, C., Baillieul, F., \& Dorey, S. (2010). Rhamnolipid biosurfactants as new players in animal and plant defense against microbes. International Journal of Molecular Sciences, 11(12), 5095-5108. http://dx.doi.org/10.3390/ijms11125095. PMid:21614194. 